\title{
Navafenterol (AZD8871) in patients with COPD: a randomized, double-blind, phase I study evaluating safety and pharmacodynamics of single doses of this novel, inhaled, long- acting, dual-pharmacology bronchodilator
}

Dave Singh ${ }^{1 *}$, Victor Balaguer ${ }^{2}$, Carol Astbury ${ }^{2}$, Ulrika Wählby-Hamrén ${ }^{3}$, Eulalia Jimenez ${ }^{4}$, Beatriz Seoane ${ }^{5}$, Cristina Villarroel ${ }^{6}$, Alejhandra Lei ${ }^{7}$, Ajay Aggarwal ${ }^{8}$ and loannis Psallidas ${ }^{9}$

\begin{abstract}
Background: Navafenterol (AZD8871) is a dual-pharmacology muscarinic antagonist $\beta_{2}$ agonist (MABA) molecule in development for the treatment of chronic obstructive pulmonary disease (COPD). The pharmacodynamics, safety and tolerability of single doses of navafenterol were investigated in patients with moderate to severe COPD.

Methods: This was a randomized, five-way complete cross-over study. Patients received single doses of navafenterol $400 \mu \mathrm{g}$, navafenterol $1800 \mu \mathrm{g}$ and placebo (all double-blind) and indacaterol $150 \mu \mathrm{g}$ and tiotropium $18 \mathrm{\mu g}$ (both open-label active comparators). The primary pharmacodynamic endpoint was change from baseline in trough forced expiratory volume in $1 \mathrm{~s}\left(\mathrm{FEV}_{1}\right)$ on day 2. Safety and tolerability were monitored throughout.

Results: Thirty-eight patients were randomized and 28 (73.7\%) completed the study. Navafenterol $400 \mu \mathrm{g}$ and $1800 \mu \mathrm{g}$ demonstrated statistically significant improvements vs placebo in change from baseline in trough $\mathrm{FEV}_{1}$ (least squares mean [95\% confidence interval]: $0.111[0.059,0.163] \mathrm{L}$ and $0.210[0.156,0.264] \mathrm{L}$, respectively, both $P<.0001$ ). The changes were significantly greater with navafenterol $1800 \mu \mathrm{g}$ vs the active comparators (least squares mean treatment difference: $0.065-0.069 \mathrm{~L}$, both $P<.05$ ). The frequency of treatment-emergent adverse events was similar for placebo and the active comparators (range 34.4-37.5\%), slightly higher for navafenterol $400 \mu \mathrm{g}(52.9 \%)$, and lowest for navafenterol $1800 \mu \mathrm{g}$ (22.6\%).
\end{abstract}

Conclusions: Both doses of navafenterol demonstrated sustained bronchodilation over $24 \mathrm{~h}$. Navafenterol was well tolerated and no safety concerns were raised.

Trial registry: ClinicalTrials.gov; No.: NCT02573155; URL: www.clinicaltrials.gov. Registered 9th October, 2015.

Keywords: Bronchodilator, COPD, MABA, Dual-pharmacology muscarinic receptor antagonist $\beta_{2}$-adrenoceptor agonist, Safety, Pharmacokinetics

\footnotetext{
* Correspondence: dsingh@meu.org.uk

${ }^{1}$ The Medicines Evaluation Unit, Centre for Respiratory and Allergy Medicine, University of Manchester, University Hospital of South Manchester NHS Foundation Trust, M23 9QZ, Manchester, UK

Full list of author information is available at the end of the article
}

C C The Author(s). 2020 Open Access This article is licensed under a Creative Commons Attribution 4.0 International License, which permits use, sharing, adaptation, distribution and reproduction in any medium or format, as long as you give appropriate credit to the original author(s) and the source, provide a link to the Creative Commons licence, and indicate if changes were made. The images or other third party material in this article are included in the article's Creative Commons licence, unless indicated otherwise in a credit line to the material. If material is not included in the article's Creative Commons licence and your intended use is not permitted by statutory regulation or exceeds the permitted use, you will need to obtain permission directly from the copyright holder. To view a copy of this licence, visit http://creativecommons.org/licenses/by/4.0/ The Creative Commons Public Domain Dedication waiver (http://creativecommons.org/publicdomain/zero/1.0/) applies to the data made available in this article, unless otherwise stated in a credit line to the data. 


\section{Background}

Inhaled long-acting bronchodilators are integral in the pharmacological management of chronic obstructive pulmonary disease (COPD). Whilst bronchodilator monotherapy is recommended for treatment initiation in many patients with COPD [1], there is considerable evidence that the combination of a long-acting muscarinic receptor antagonist (LAMA) with a long-acting $\beta_{2}$-agonist (LABA) offers additional benefits over monotherapy [2, 3]. The Global Initiative for Chronic Obstructive Lung Disease (GOLD) report recommends a combination of a LAMA and LABA for treatment escalation, or initiation, in patients with greater symptom burden or exacerbation risk [1].

Co-formulation of fixed-dose combinations (FDCs), including LAMA/LABA combinations, is technically challenging [4]. The development of dual-pharmacology muscarinic antagonist $\beta_{2}$ agonist (MABA) molecules offers a new approach to the treatment of COPD [4]. These molecules combine two mechanisms of action within a single entity, offering potential advantages such as the delivery of a fixed ratio of LAMA/LABA activity into each lung region, simplification of technical and clinical development, and the potential for additive or synergistic bronchodilation over either entity alone [4, 5]. The use of MABAs also creates a platform for the inclusion of another drug, such as an inhaled corticosteroid (ICS) or another anti-inflammatory agent [4]. Navafenterol (AZD8871, formerly LAS191351) is one of the few MABAs in clinical development for the treatment of COPD. Its pharmacological profile has been extensively studied in preclinical investigations in vitro and in vivo, and these investigations have confirmed its dual action at $\beta_{2}$ - and muscarinic receptors [6].

A study of navafenterol was conducted in two parts: a first-in-human single ascending-dose study in patients with mild, persistent asthma (Part 1) and a five-way crossover, single-dose study in patients with moderate to severe COPD (Part 2). In Part 1, single ascending doses of navafenterol 50, 200, 400, 900, 1800, and $2100 \mu \mathrm{g}$ were well tolerated and doses $\geq 200 \mu \mathrm{g}$ produced clinically meaningful, sustained bronchodilation [7]. Here, we report data from Part 2 of this study; the primary objective was to assess the pharmacodynamics, safety, and tolerability of single doses of navafenterol in patients with moderate to severe COPD, with exploratory comparisons vs placebo and the active comparators indacaterol (a LABA) and tiotropium (a LAMA).

\section{Methods}

\section{Study design}

This was a randomized, double-blind, five-way complete crossover, placebo and active-controlled single-dose study (NCT02573155). A subset of patients participated in a pharmacokinetic (PK) sub-study, the methods and results of which are reported in Additional file 1 . The study was conducted at a single site in the UK (Medicines Evaluation Unit, Manchester). The study protocol was approved by an Independent Ethics Committee (NRES Committee - Cambridgeshire and Hertfordshire, Health Research Authority, Nottingham, UK; Reference No 15/EE/0329; see Additional file 1) and the UK Medicines and Healthcare Products Regulatory Agency. The informed consent form was also reviewed by the Independent Ethics Committee. The study was performed in accordance with the Declaration of Helsinki and the International Conference on Harmonization/Good Clinical Practice guidelines. All patients provided written, informed consent before enrolment in the study. The first patient was randomized on April 25, 2016; the last patient visit was August 22, 2016.

Following a screening evaluation (Fig. 1) and run-in period of 14 to 28 days, patients were assigned to one of 10 treatment sequences, each with a 1:1:1:1:1 randomization ratio, according to a William's design for crossover studies (Fig. 2). There were five treatment periods, with patients remaining on-site for $36 \mathrm{~h}$ post-dose in each treatment period. The treatments administered were navafenterol $400 \mu \mathrm{g}$, navafenterol $1800 \mu \mathrm{g}$, and placebo (all double blind, each administered via a variant of the Genuair $^{\text {rm }} /$ Pressair $^{\oplus \mathrm{a}}$ dry-powder inhaler [DPI] adapted internally to deliver a single dose of inhalation powder) and indacaterol $150 \mu \mathrm{g}$ and tiotropium $18 \mu \mathrm{g}$ (both open-label, delivered by Onbrez Breezhaler ${ }^{\ominus}$ and HandiHaler ${ }^{\bullet}$ DPIs, respectively). A single dose was administered at the same time $( \pm 1 \mathrm{~h})$ on day 1 of each treatment period, between $7 \mathrm{am}$ and $10 \mathrm{am}$. There was a washout period of 10 to 21 days following navafenterol or placebo treatment and 7 to 21 days following indacaterol or tiotropium treatment.

Patients were withdrawn from their usual COPD therapy after signing the informed consent form but maintained on their usual ICS dose; those receiving an ICS/ LABA FDC were switched to ICS monotherapy. Salbutamol was provided as reliever medication for the duration of the study.

A follow-up visit was performed $7( \pm 2)$ days after the last dose or after discontinuation. Patients were contacted by telephone $14( \pm 2)$ days after the last dose, to record any adverse events (AEs).

\section{Patients}

Male and female (of non-child-bearing potential) patients aged $\geq 40$ years with a clinical diagnosis of stable moderate to severe COPD according to GOLD 2015 criteria [8] were eligible for inclusion. Other inclusion criteria included: postbronchodilator forced expiratory volume in $1 \mathrm{~s}\left(\mathrm{FEV}_{1}\right)<80 \%$ and $\geq 30 \%$ predicted normal 


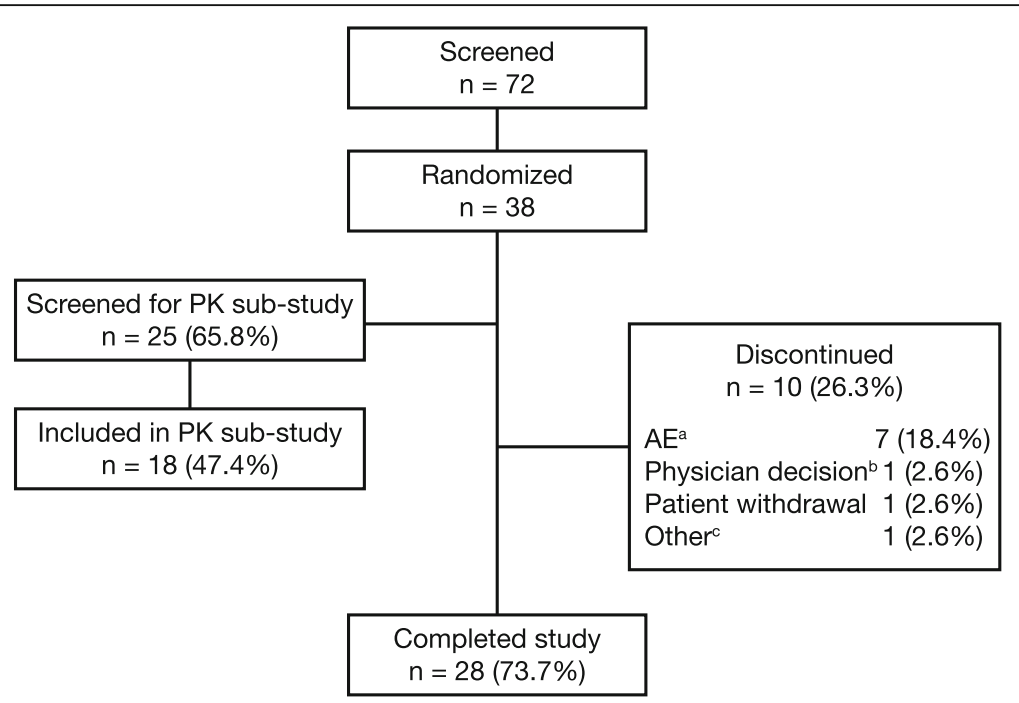

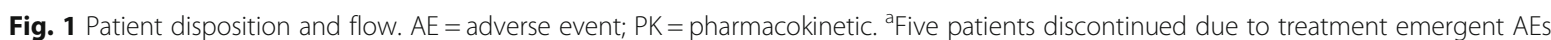
leading to study drug discontinuation, 1 patient withdrew due to a treatment emergent AE during the washout period, and 1 withdrew due to a non-treatment-emergent $\mathrm{AE}_{\text {; }}{ }^{\mathrm{b}}$ patient had a positive drug screen test for cocaine; ${ }^{c}$ patient did not meet stability/variability criteria

and $\mathrm{FEV}_{1} /$ forced vital capacity $(\mathrm{FVC})$ ratio $<70 \%$; body mass index $<40 \mathrm{~kg} / \mathrm{m}^{2}$, current or ex-smoker with a smoking history of $\geq 10$ pack-years, no evidence of clinically significant respiratory and/or cardiovascular conditions or laboratory abnormalities and no history of thoracic surgery. Other inclusion and exclusion criteria and study restrictions are reported in Additional file 1.

\section{Assessments}

\section{Pharmacodynamics}

The primary pharmacodynamic endpoint was change from baseline in trough $\mathrm{FEV}_{1}$. Trough $\mathrm{FEV}_{1}$ was the mean of the $\mathrm{FEV}_{1}$ values obtained at $23 \mathrm{~h}$ and $24 \mathrm{~h}$ after study drug administration. Secondary endpoints included change from baseline in normalized $\mathrm{FEV}_{1}$ area under the curve from 0 to $6 \mathrm{~h}\left(\mathrm{AUC}_{0-6}\right), 0-12 \mathrm{~h}\left(\mathrm{AUC}_{0-12}\right), 12-24 \mathrm{~h}$ $\left(\mathrm{AUC}_{12-24}\right)$, and $0-24 \mathrm{~h}\left(\mathrm{AUC}_{0-24}\right)$ post-dose, change from baseline in $\mathrm{FEV}_{1}$ at each scheduled timepoint postdose, number and percentage of patients achieving $\geq 100$ $\mathrm{mL}$ change from baseline in $\mathrm{FEV}_{1}$ (minimal clinically important difference) during the $6 \mathrm{~h}$ post-dose, change from baseline in and time to peak $\mathrm{FEV}_{1}$ on day 1 , and change from baseline in trough FVC on day 2.

Details of the timing and measurement standards for $\mathrm{FEV}_{1}$ and $\mathrm{FVC}$ assessments are provided in Additional file 1.

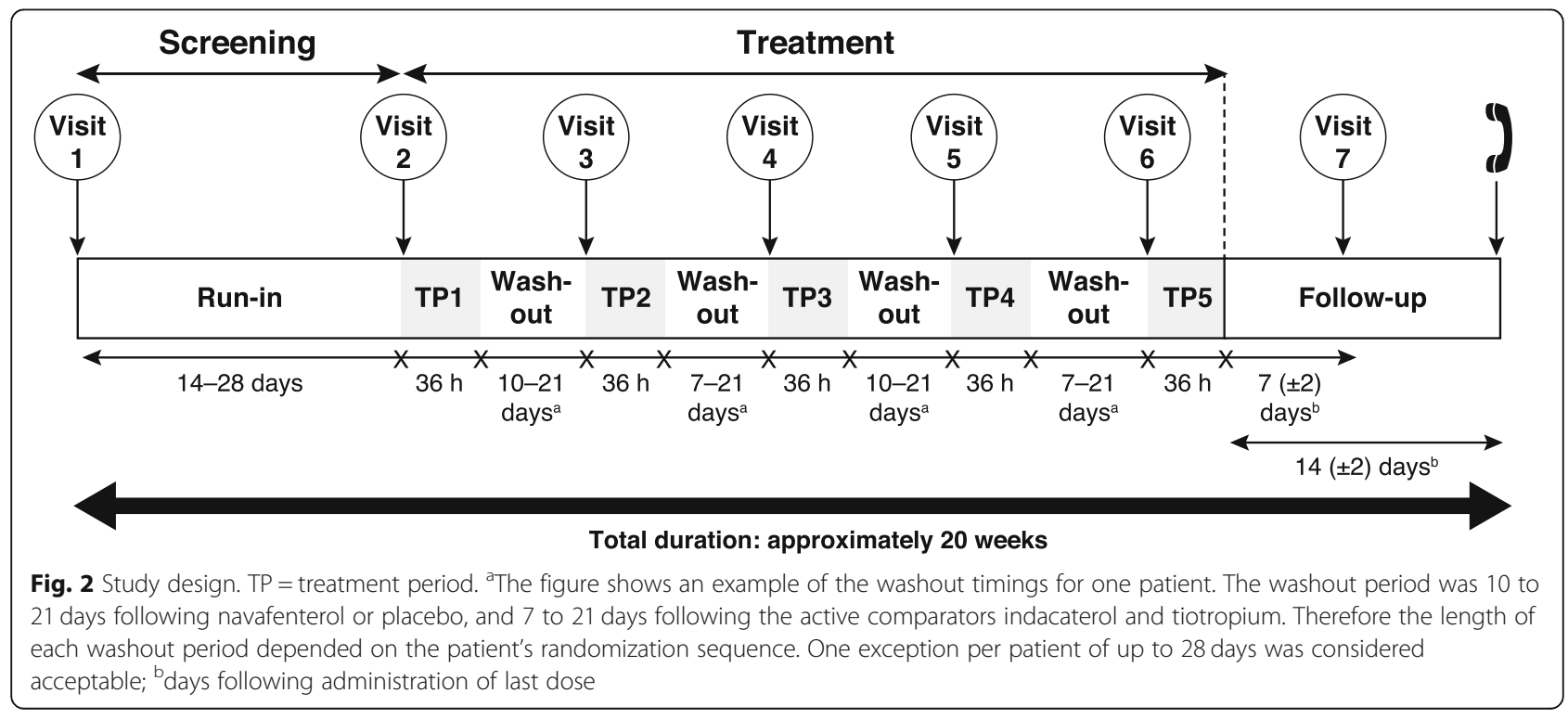




\section{Safety and tolerability}

AEs were collected from consent until the telephone follow-up. Treatment-emergent AEs (TEAEs) were defined as AEs that appeared or worsened after the first dose of study drug and within 14 days following the last dose. Other safety assessments included physical examination, blood pressure, clinical laboratory assessments (blood chemistry, hematology, urinalysis, and blood potassium and glucose [both measured via i-STAT]), and 12-lead electrocardiography (see Additional file 1).

\section{Statistical analysis}

There was no formal sample size calculation. It was considered that a sample size of 30 patients would be sufficient to meet the objectives of the study. Approximately 40 patients were randomized to account for an approximate $25 \%$ dropout rate.

Pharmacodynamic variables were analyzed in the per protocol population, defined as all randomized patients who satisfied the main inclusion/exclusion criteria, completed at least one treatment period, and had no major protocol violations. All primary and secondary pharmacodynamic variables, with the exception of time to peak $\mathrm{FEV}_{1}$, were analyzed by an analysis of covariance model for crossover designs. All statistical comparisons used 2sided hypothesis tests, and the significance level was set at .05 without multiplicity adjustment. Further details are in Additional file 1.

Safety outcomes were analyzed descriptively in the safety population (all randomized patients who received at least one dose of the study drug).

SAS version 9.2 or later (SAS Institute, Inc., Cary, NC) was used for all statistical analyses.

\section{Results}

\section{Patient demographics and baseline characteristics}

A total of 72 patients were screened; of these, 38 were randomized and 28 (73.7\%) completed the study (Fig. 1). Patient demographics and baseline characteristics for the safety population are presented in Table 1. Twenty-two (57.9\%) patients had moderate airflow limitation and 16 (42.1\%) had severe airflow limitation. Mean (standard deviation [SD]) $\mathrm{FEV}_{1}$ absolute reversibility was 217 (124) $\mathrm{mL}$. Mean percentage (SD) bronchodilator reversibility was $19.9 \%(13.7 \%)$. Nineteen patients $(50.0 \%)$ demonstrated reversibility (postbronchodilator increase in $\mathrm{FEV}_{1} \geq 12 \%$ and $\geq 200 \mathrm{~mL}$ ).

\section{Pharmacodynamics}

All active treatments showed statistically significant improvements vs placebo in change from baseline in trough $\mathrm{FEV}_{1}$ (Fig. 3a; Table 2; least squares [LS] mean treatment difference: navafenterol $400 \mu \mathrm{g}, 0.111 \mathrm{~L}$; navafenterol $1800 \mu \mathrm{g}, 0.210 \mathrm{~L}$; indacaterol $150 \mu \mathrm{g}, 0.141 \mathrm{~L}$;
Table 1 Patient Demographics and Baseline Characteristics (Safety Population)

\begin{tabular}{|c|c|}
\hline Baseline Characteristic & Total \\
\hline Number of patients in safety population & 38 \\
\hline Age, years & $65.6(6.4)$ \\
\hline Male, $n(\%)$ & $22(57.9)$ \\
\hline White, $n(\%)$ & $38(100)$ \\
\hline Body mass index, $\mathrm{kg} / \mathrm{m}^{2}$ & $27.7(3.5)$ \\
\hline \multicolumn{2}{|l|}{ Smoking status, $n(\%)$} \\
\hline Current & $14(36.8)$ \\
\hline Former & $24(63.2)$ \\
\hline Smoking consumption, pack-years & $45.4(26.8)$ \\
\hline \multicolumn{2}{|l|}{ COPD severity, $n(\%)$} \\
\hline Moderate & $22(57.9)$ \\
\hline Severe & $16(42.1)$ \\
\hline Duration of COPD, years & $9.5(5.9)$ \\
\hline \multicolumn{2}{|c|}{ Number of COPD exacerbations in previous 12 months, $n(\%)$} \\
\hline 1 & $8(21.1)$ \\
\hline 2 & $6(15.8)$ \\
\hline 3 & $2(5.3)$ \\
\hline Postbronchodilator \% predicted $\mathrm{FEV}_{1}$ & $52.0(12.5)$ \\
\hline Postbronchodilator $\mathrm{FEV}_{1} / \mathrm{FVC}$ & $45.8(10.2)$ \\
\hline Bronchial reversibility, \% & $19.89(13.72)$ \\
\hline $\mathrm{FEV}_{1}$ absolute reversibility, $\mathrm{L}$ & $0.217(0.124)$ \\
\hline
\end{tabular}

COPD chronic obstructive pulmonary disease, $F E V_{1}$ forced expiratory volume in $1 \mathrm{~s}, F V C$ forced vital capacity

Data are mean (standard deviation) unless otherwise stated

tiotropium $18 \mu \mathrm{g}, 0.145 \mathrm{~L}$; all $P<.0001)$. The magnitude of change in trough $\mathrm{FEV}_{1}$ was greater with navafenterol $1800 \mu \mathrm{g}$ compared with both active comparators (LS mean treatment difference $0.065-0.069 \mathrm{~L}$, both $P<.05$ ). A similar pattern of results with a greater effect of navafenterol $1800 \mu \mathrm{g}$ compared with both active comparators was observed for change from baseline in normalized $\mathrm{FEV}_{1} \mathrm{AUC}_{0-24}, \mathrm{AUC}_{0-12}$, and $\mathrm{AUC}_{12-24}$. Navafenterol $400 \mu \mathrm{g}$ also achieved statistically significant improvements vs tiotropium for $\mathrm{AUC}_{0-24}$ and $\mathrm{AUC}_{0-12}$ (Fig. 3b; Table 2).

Mean (SD) time to peak $\mathrm{FEV}_{1}$ was 3.4 (2.1) h, 3.9 (2.0) h, $3.0(2.2) \mathrm{h}$, and $3.3(2.2) \mathrm{h}$ with navafenterol $400 \mu \mathrm{g}$, navafenterol $1800 \mu \mathrm{g}$, indacaterol, and tiotropium, respectively. All active treatments showed statistically significant improvements in change from baseline in peak $\mathrm{FEV}_{1}$ vs placebo (e-Fig. 1; Table 2); navafenterol $400 \mu \mathrm{g}$, $0.218 \mathrm{~L}$; navafenterol $1800 \mu \mathrm{g}, \quad 0.285 \mathrm{~L}$; indacaterol $150 \mu \mathrm{g}, 0.227 \mathrm{~L}$; tiotropium $18 \mu \mathrm{g}, 0.139 \mathrm{~L} ; P<.01$ for all). Improvements in peak $\mathrm{FEV}_{1}$ with navafenterol $1800 \mu \mathrm{g}$ were significantly greater compared with tiotropium $(P<.01)$ but not indacaterol or navafenterol $400 \mu \mathrm{g}$. 
b

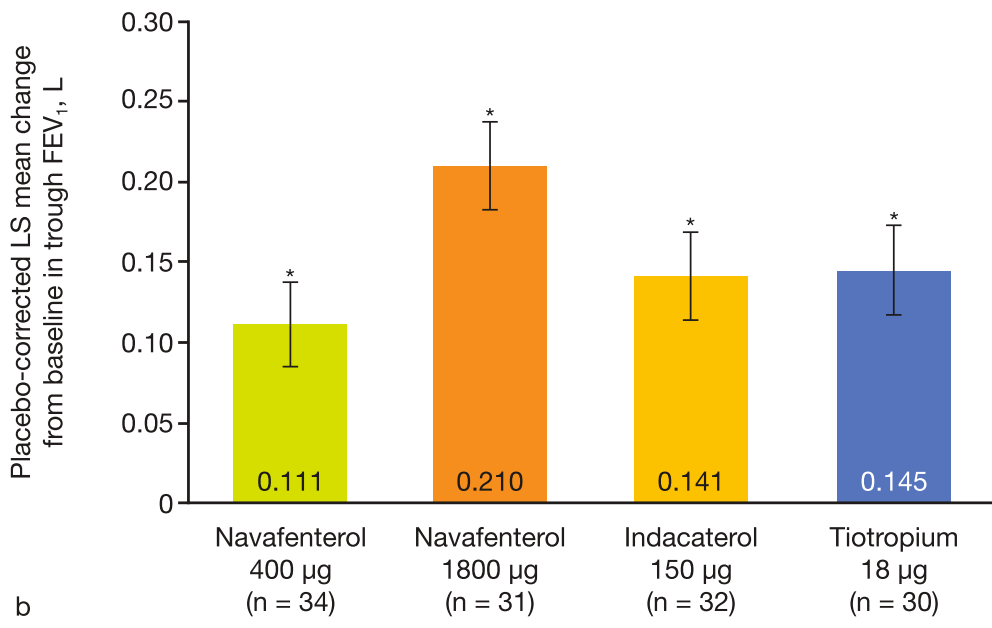

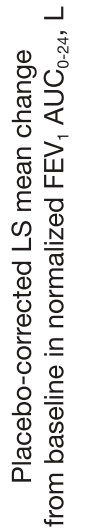

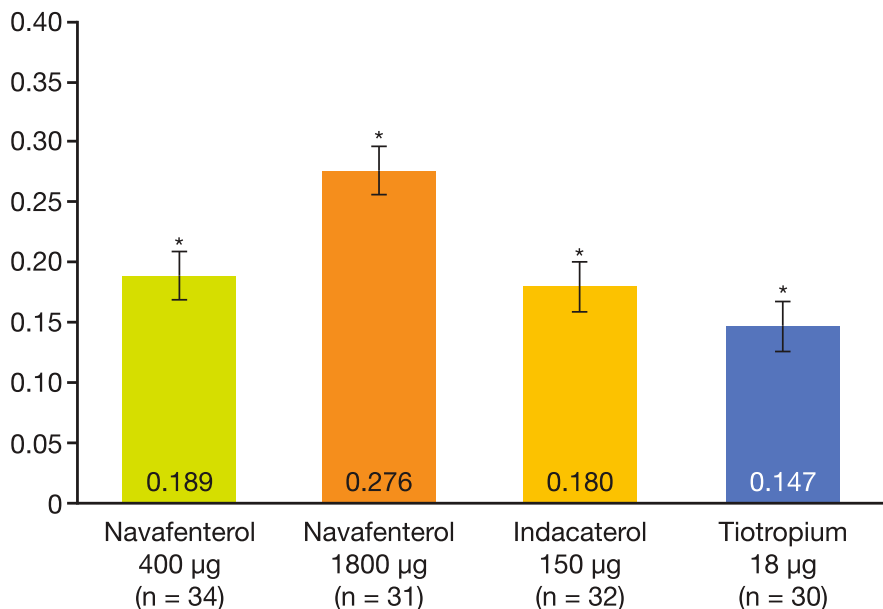

Fig. 3 Placebo-corrected mean change from baseline in a trough $\mathrm{FEV}_{1}$ at day 2 and $\mathbf{b}$ normalized $\mathrm{FEV}_{1} \mathrm{AUC}_{0-24}$ (per protocol population). Data are $L S$ means \pm standard error. $A U C_{0-24}=$ area under the curve from 0 to $24 \mathrm{~h}$ post-dose; $F E V_{1}=$ forced expiratory volume in $1 \mathrm{~s} ; L S=l e a s t$ squares. ${ }^{*} P<.0001$ vs placebo

Improvements with navafenterol $400 \mu \mathrm{g}$ were similar to those of the active comparators.

At all timepoints from $15 \mathrm{~min}$ to $36 \mathrm{~h}$ post-dose, all active treatments showed statistically significant improvements in change from baseline in $\mathrm{FEV}_{1}$ vs placebo (Fig. 4; $P<.01$ for all). Additionally, navafenterol $1800 \mu \mathrm{g}$ significantly improved change from baseline in $\mathrm{FEV}_{1}$ vs placebo at $5 \mathrm{~min}$ post-dose $(P=.0123) . \mathrm{FEV}_{1}$ data over time are further described in Additional file 1, along with the proportion of patients achieving $\geq 100 \mathrm{~mL}$ change from baseline in $\mathrm{FEV}_{1}$ and trough FVC.

\section{Safety and tolerability}

Overall, 31 (81.6\%) patients reported TEAEs (Table 3). The frequency of TEAEs was similar for placebo and the active comparators (range 34.4-37.5\%), slightly higher for navafenterol $400 \mu \mathrm{g}$ (52.9\%), and lowest for navafenterol
$1800 \mu \mathrm{g}$ (22.6\%). Overall, the most frequently reported TEAEs across all groups were headache (31.6\%) and nasopharyngitis (13.2\%). Most TEAEs were mild or moderate in intensity and there were no deaths during the study. Only one incidence of headache was considered to be related to the study treatment by the study investigator, which occurred in the tiotropium group. Five (13.2\%) patients discontinued treatment due to TEAEs, including two serious AEs (physical assault and fractured C1 vertebra) and three non-serious TEAEs (COPD exacerbation, pneumonia, and headache); none of these TEAEs were assessed as considered related to treatment.

There were no clinically significant changes in clinical laboratory tests, blood glucose and serum potassium concentrations (e-Fig. 2), heart rate, or blood pressure. Small increases in mean change from baseline in QT interval corrected for heart rate using the Fridericia 


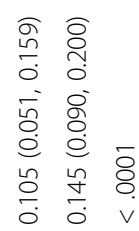

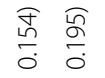

$\stackrel{\infty}{0} \stackrel{\infty}{0}^{-}$

\begin{tabular}{lll}
$e$ & $\varrho$ & $\overline{8}$ \\
$\overline{0}$ & $\overline{5}$ & 8 \\
\hdashline & $\overline{0}$ & $v$
\end{tabular}

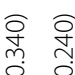

ळi

号 $\frac{0}{0} \frac{0}{0}$

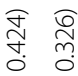

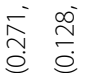

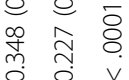

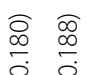

กิ

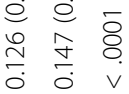

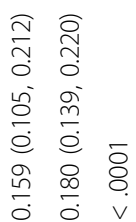

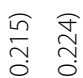

๖ั

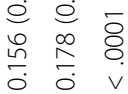

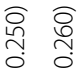

宛

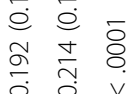

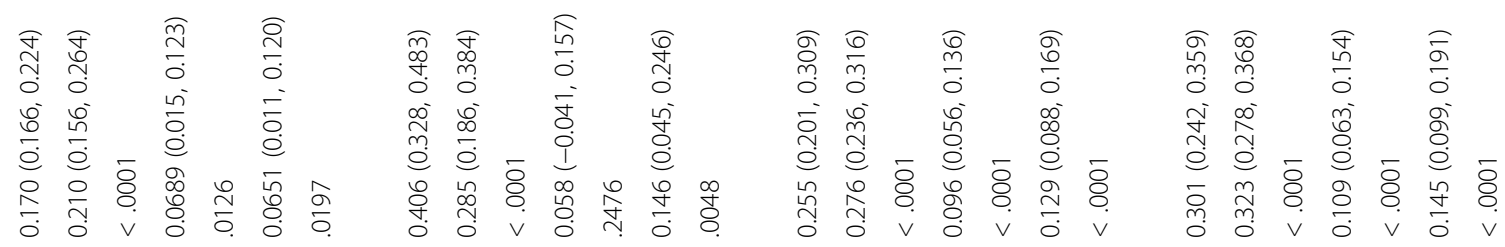

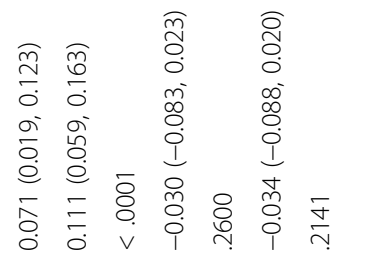

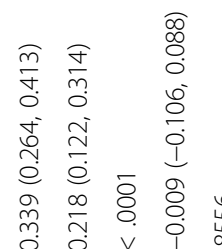

\begin{tabular}{l} 
o \\
$\stackrel{0}{0}$ \\
0 \\
0 \\
0 \\
0 \\
1 \\
\multicolumn{2}{c}{}
\end{tabular}

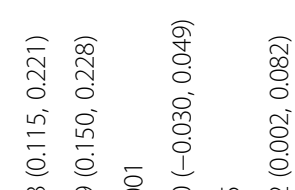

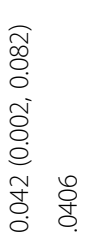

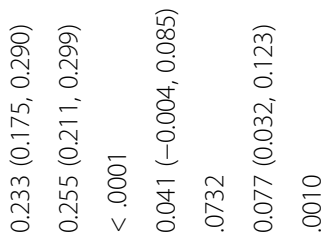

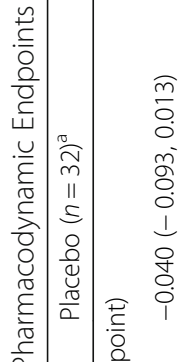

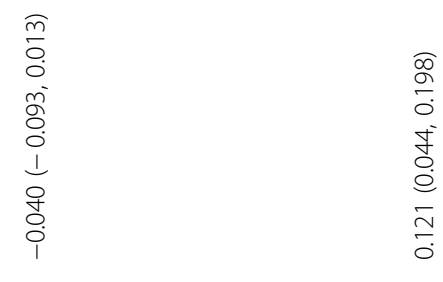

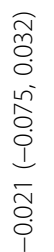

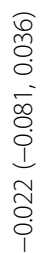

造

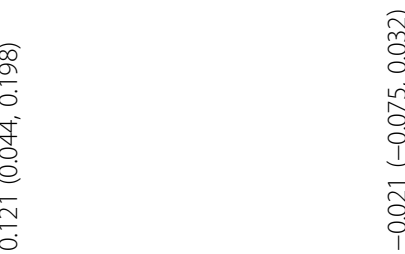<smiles>[BH2-][BH3-]</smiles>

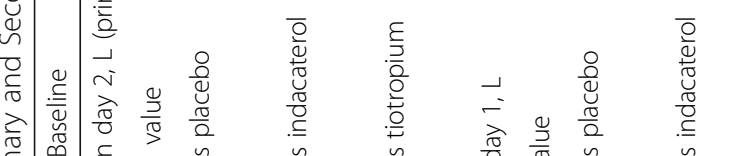




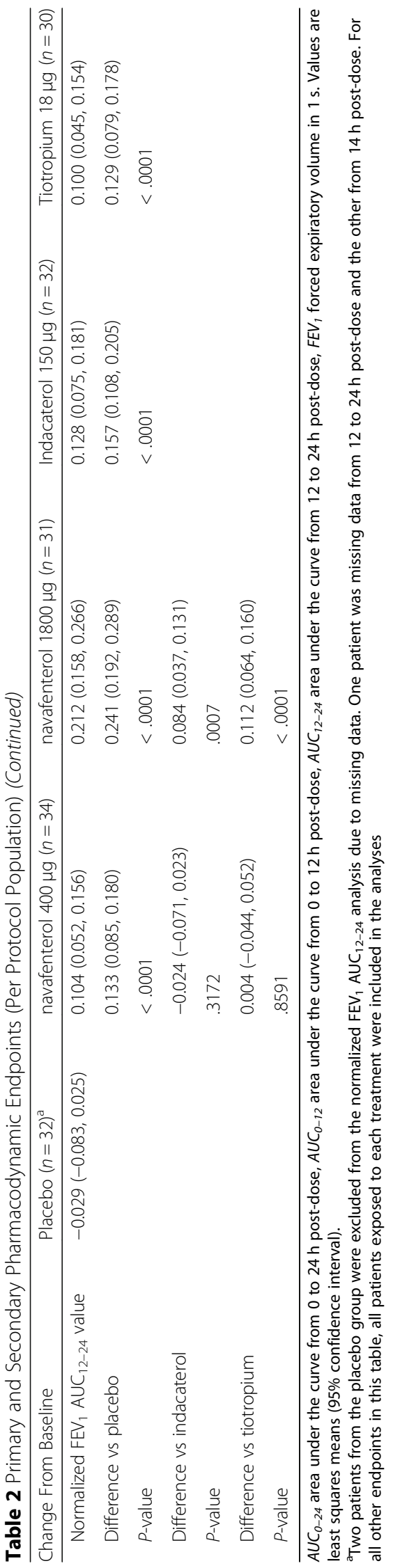




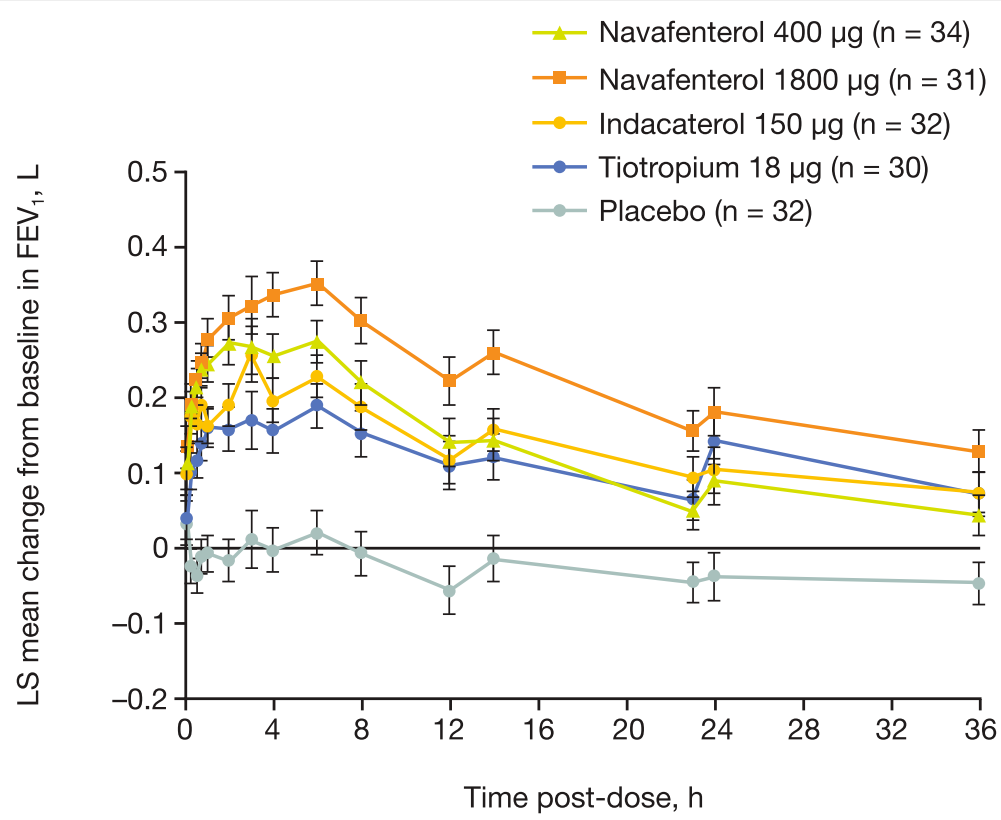

Fig. 4 Mean change from baseline in $\mathrm{FEV}_{1}$ over $36 \mathrm{~h}$ (per protocol population). Data are LS means \pm standard error. The number of patients exposed to each treatment differed from the number of non - missing observations for navafenterol $1800 \mu \mathrm{g}$ (at $45 \mathrm{~min}$ and $2 \mathrm{~h}$; both $n=30$ ) and placebo (at 12 and $14 \mathrm{~h} ; n=31$ and $n=30$, respectively). $\mathrm{FEV}_{1}=$ forced expiratory volume in $1 \mathrm{~s}$; LS = least squares

formula $(\mathrm{QTCF})$ were observed in all active treatment groups compared with placebo; the largest increase in LS mean (90\% confidence interval) change from baseline in QTcF vs placebo was observed $3 \mathrm{~h}$ post-dose with navafenterol $400 \mu \mathrm{g}(3.05[0.106,6.00] \mathrm{ms})$ and navafenterol $1800 \mu \mathrm{g}(5.04[2.01,8.06] \mathrm{ms}), 2 \mathrm{~h}$ post-dose with indacaterol $(4.38[1.84,6.92] \mathrm{ms})$, and $36 \mathrm{~h}$ post-dose with tiotropium $(3.98[1.27,6.69] \mathrm{ms})$. Seven male patients met the criteria for potentially clinically significant QTcF increase, including 6 patients with QTcF values $>450 \mathrm{~ms}$ and 1 patient with an increase from baseline $>30 \mathrm{~ms}$; none of these abnormalities were considered clinically significant by the investigator or reported as TEAEs. QTcF values $>450 \mathrm{~ms}$ were observed sporadically in all active treatment groups at all timepoints (including baseline) with no clear pattern observed (Fig. 5).

\section{Discussion}

Single doses of navafenterol $400 \mu \mathrm{g}$ and $1800 \mu \mathrm{g}$ produced sustained bronchodilation over $24 \mathrm{~h}$ in patients with moderate to severe COPD, with significant improvements of $0.111 \mathrm{~L}$ and $0.210 \mathrm{~L}$, respectively, in trough $\mathrm{FEV}_{1}$ vs placebo. The magnitude of the changes was significantly greater with navafenterol $1800 \mu \mathrm{g}$ compared with the active comparators, indacaterol $(0.069 \mathrm{~L})$ and tiotropium $(0.065 \mathrm{~L})$. Both doses of navafenterol significantly

Table 3 Frequency of TEAEs Overall and Occurring in $\geq 2$ Patients, by MedDRA ${ }^{a}$ Preferred Term (Safety Population)

\begin{tabular}{|c|c|c|c|c|c|c|}
\hline TEAE (Preferred Term ${ }^{\mathrm{a}}$ ) & $\begin{array}{l}\text { Placebo }(n= \\
32)\end{array}$ & $\begin{array}{l}\text { navafenterol } 400 \mu \mathrm{g} \\
(n=34)\end{array}$ & $\begin{array}{l}\text { navafenterol } 1800 \mu \mathrm{g} \\
(n=31)\end{array}$ & $\begin{array}{l}\text { Indacaterol } 150 \mu \mathrm{g} \\
(n=32)\end{array}$ & $\begin{array}{l}\text { Tiotropium } 18 \mu \mathrm{g} \\
(n=30)\end{array}$ & $\begin{array}{l}\text { All }(N= \\
38)\end{array}$ \\
\hline Any event, n (\%) & $11(34.4)$ & $18(52.9)$ & $7(22.6)$ & $12(37.5)$ & $11(36.7)$ & $31(81.6)$ \\
\hline Headache & $7(21.9)$ & $5(14.7)$ & $3(9.7)$ & $4(12.5)$ & $7(23.3)$ & $12(31.6)$ \\
\hline Nasopharyngitis & $1(3.1)$ & $1(2.9)$ & $1(3.2)$ & $2(6.3)$ & $1(3.3)$ & $5(13.2)$ \\
\hline COPD & 0 & $2(5.9)$ & $1(3.2)$ & $1(3.1)$ & 0 & $4(10.5)$ \\
\hline Erythema & $1(3.1)$ & $1(2.9)$ & 0 & $1(3.1)$ & 0 & $3(7.9)$ \\
\hline $\begin{array}{l}\text { Medical device site } \\
\text { reaction }\end{array}$ & $1(3.1)$ & 0 & $1(3.2)$ & $1(3.1)$ & 0 & $3(7.9)$ \\
\hline Constipation & $1(3.1)$ & $1(2.9)$ & $1(3.2)$ & 0 & 0 & $2(5.3)$ \\
\hline Nausea & $1(3.1)$ & $1(2.9)$ & 0 & 0 & 0 & $2(5.3)$ \\
\hline Rhinitis & 0 & $1(2.9)$ & 0 & $1(3.1)$ & 0 & $2(5.3)$ \\
\hline
\end{tabular}




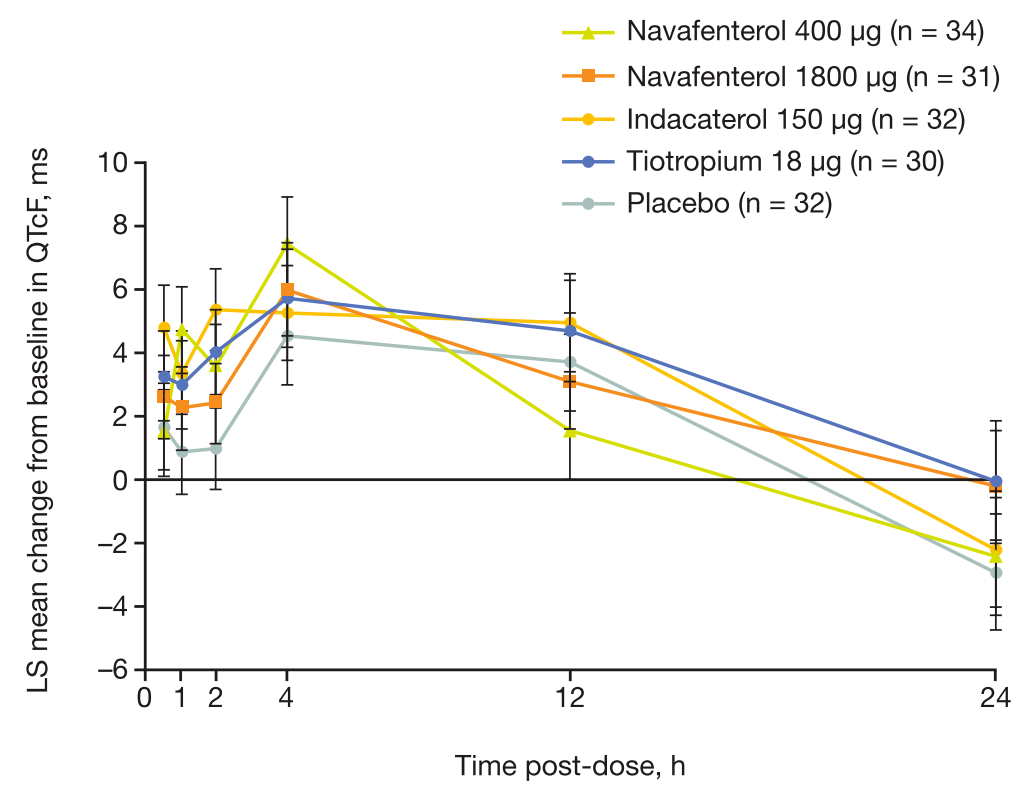

Fig. 5 Mean change from baseline in QTcF over time (safety population). Data are LS means \pm standard error. QTcF = QT interval corrected for heart rate using the Fridericia formula; $L S=$ least squares

improved change from baseline in normalized $\mathrm{FEV}_{1}$ $\mathrm{AUC}_{0-24}$ vs placebo and tiotropium, with navafenterol $1800 \mu \mathrm{g}$ also improving this parameter vs indacaterol.

The changes from baseline in trough $\mathrm{FEV}_{1}$ with both doses of navafenterol exceeded the minimal clinically important difference of $0.100 \mathrm{~L}$ vs placebo [9]. The magnitude of change in trough $\mathrm{FEV}_{1}$ vs placebo with navafenterol $400 \mu \mathrm{g}$ $(0.111 \mathrm{~L})$ and $1800 \mu \mathrm{g}(0.210 \mathrm{~L})$ was similar to that observed with single doses of the MABA, batefenterol, in a population of patients with moderate COPD (FEV 50 to $80 \%$ predicted; patients with $>2$ exacerbations in the previous 12 months excluded), at doses of $400 \mu \mathrm{g}(0.141 \mathrm{~L})$ and $1200 \mu \mathrm{g}(0.184 \mathrm{~L})$ [10]. Both doses of navafenterol demonstrated a rapid onset of action (within 5-15 min post-dose), with changes from baseline in peak $\mathrm{FEV}_{1}$ vs placebo of $0.218 \mathrm{~L}$ and $0.285 \mathrm{~L}$ with navafenterol $400 \mu \mathrm{g}$ and $1800 \mu \mathrm{g}$, respectively.

One limitation of the study was the inclusion of active comparators as monotherapy rather than combination therapy, meaning that no conclusions can be drawn about the efficacy of AZD8771 compared with LAMA/ LABA FDCs. However, the magnitude of the treatment difference between navafenterol $1800 \mu \mathrm{g}$ and indacaterol $150 \mu \mathrm{g}$ for trough $\mathrm{FEV}_{1}(0.069 \mathrm{~L})$ was similar to that observed between the LAMA/LABA FDC DPI glycopyrronium/indacaterol $50 / 110 \mu \mathrm{g}$ and indacaterol $150 \mu \mathrm{g}$ $(0.07 \mathrm{~L})$ in a 26 -week study in patients with moderate to severe COPD [11]. Similarly, the treatment difference between navafenterol $1800 \mu \mathrm{g}$ and the LAMA tiotropium $18 \mu \mathrm{g}(0.065 \mathrm{~L})$ was similar to that observed between tiotropium/olodaterol $5 / 5 \mu \mathrm{g}$ FDC delivered via soft mist inhaler and tiotropium $5 \mu \mathrm{g}(0.050-0.071 \mathrm{~L})$ after 24 weeks' treatment in patients with moderate to very severe COPD [12]. Whilst it is difficult to draw firm conclusions across studies due to differences in methodologies, these results suggest that navafenterol $1800 \mu \mathrm{g}$ may provide similar benefits to LAMA/LABA combinations compared with monotherapy. It is important to note that the above-mentioned studies report data following repeat dosing, and the current study was limited by its single-dose design; however, a greater bronchodilatory response for navafenterol has also been achieved with repeat-dosing vs single-dosing [13]. Furthermore, a 4-week study with batefenterol found that greater improvements in $\mathrm{FEV}_{1}$ were observed on day 28 compared with day 1 for all doses investigated [14].

The pharmacokinetic data generated for navafenterol are consistent with the rapid onset of action and sustained bronchodilation observed in the pharmacodynamic response. Navafenterol is rapidly absorbed into the bloodstream (median time to maximum concentration $1-2 \mathrm{~h}$ ) and slowly eliminated from plasma.

Single doses of navafenterol were well tolerated and no safety concerns were identified. The only TEAE occurring in more than two patients in the navafenterol treatment groups was headache; however, its frequency was lower than in the placebo group. Small increases in the duration of QTcF were observed with both doses of navafenterol; however, the upper limit of the $90 \%$ confidence interval for the largest QTcF change from baseline vs placebo was $<10 \mathrm{~ms}$. Possible effects of navafenterol on QTcF interval require further evaluation in larger clinical trials with repeat dosing. There were no clinically 
significant changes in blood glucose and potassium concentrations in the present study.

The proportion of reversible patients in this study was possibly due to the small sample size of the trial. This may have contributed to the effects on lung function observed with navafenterol and the active controls. However, the effects on trough $\mathrm{FEV}_{1}$ with navafenterol in this part of the study are in line with the effect size seen in the phase $2 \mathrm{a}$ study that only included reversible patients [15]. Since statistical comparisons between navafenterol and the active comparators were made using ANCOVA with no correction for multiple testing, statistical significance should be interpreted with caution, considering the lack of overall control of the type I error. Since this was a first-time-in-human phase I study, additional studies with navafenterol and larger sample sizes will be conducted to elucidate the efficacy of the drug as it progresses through development.

\section{Conclusion}

Both doses of navafenterol demonstrated rapid onset of action (within 5-15 min post-dose) and sustained bronchodilation over $24 \mathrm{~h}$. The bronchodilatory efficacy of navafenterol $1800 \mu \mathrm{g}$ was greater than that of both indacaterol $150 \mu \mathrm{g}$ and tiotropium $18 \mu \mathrm{g}$. Overall, navafenterol was well tolerated and no safety concerns were raised. These results support the continued clinical development of navafenterol.

${ }^{\mathrm{a}}$ Registered trademarks of the AstraZeneca group of companies; for use within the USA as Pressair ${ }^{\circ}$ and Genuair $^{\mathrm{rn}}$ within all other licensed territories.

\section{Supplementary information}

Supplementary information accompanies this paper at https://doi.org/10. 1186/s12931-020-01347-7.

Additional file 1: Additional information. The e-Appendices, e-Tables and e-Figures can be found in the Supplemental Materials section of the online article.

\section{Abbreviations}

AE: Adverse event; $\mathrm{AUC}_{0-\infty}$ : Area under the concentration-time curve from time zero extrapolated to infinity; $A_{U} C_{0-t}$ : Area under the concentration-time curve from zero to the last quantifiable measurable concentration; $\mathrm{AUC}_{0-}$ 6: Area under the curve from 0 to $6 \mathrm{~h}$ post-dose; $\mathrm{AUC}_{0-12}$ : Area under the curve from 0 to $12 \mathrm{~h}$ post-dose; $\mathrm{AUC}_{0-24}$ : Area under the curve from 0 to 24 $\mathrm{h}$ post-dose; $\mathrm{AUC}_{12-24}$ : Area under the curve from $12 \mathrm{~h}$ to $24 \mathrm{~h}$ post-dose; COPD: Chronic obstructive pulmonary disease; DPI: Dry-powder inhaler; FDC: Fixed dose combination; FEV 1 : Forced expiratory volume in $1 \mathrm{~s}$; GOLD: Global Initiative for Chronic Obstructive Lung Disease; FVC: Forced vital capacity; ICS: Inhaled corticosteroid; LABA: Long-acting $\beta_{2}$-adrenoceptor agonist; LAMA: Long-acting muscarinic receptor antagonist; LS: Least squares; MABA: Muscarinic receptor antagonist and $\beta_{2}$-adrenoceptor agonist; PK: Pharmacokinetic; QTCF: QT interval corrected for heart rate using the Fridericia formula; SD: Standard deviation; TEAE: Treatment-emergent adverse event
}

\section{Acknowledgements}

The authors would like to thank the patients and their families, as well as the investigators and site staff who participated in this study. Dave Singh is supported by the National Institute for Health Research (NIHR) Manchester Biomedical Research Centre (BRC).

\section{About this supplement}

This article has been published as part of Respiratory Research, Volume 21 Supplement 1, 2020: Results from the Phase I study programme for navafenterol (AZD8871), a novel inhaled dual pharmacology bronchodilator (MABA). The full contents of the supplement are available at https://respiratoryresearch.biomedcentral.com/articles/supplements/volume-21-supplement-1.

\section{Authors' contributions}

D. S. was an investigator in the study and contributed to the interpretation of data. C. A., U. W. H., L. J., B. S., C. V., A. L., and A. A. conceived the study and $\mathrm{V}$. B. managed the study. All authors contributed to the interpretation of data. All authors critically reviewed the manuscript and approved the final version for submission. All named authors meet the International Committee of Medical Journal Editors criteria for authorship of this manuscript, take responsibility for the integrity of the work as a whole, and have given final approval for the version to be published. D. S. takes responsibility for (is the guarantor of) the content of the manuscript, including the data and analysis.

\section{Funding}

This study was funded by AstraZeneca. Navafenterol is an investigational product with no approved indication. Article processing charges were funded by AstraZeneca. Medical writing support, under the direction of the authors, was provided by Suzanne McAllister, PhD, on behalf of CMC CONNECT, a division of Complete Medical Communications Ltd., Macclesfield, UK, funded by AstraZeneca, in accordance with Good Publication Practice (GPP3) guidelines [16]. The study and article processing charges were funded by AstraZeneca. Current or former employees of AstraZeneca (V. B., C. A., U. W. H., L. J., B. S., C. V., A. L., A. A., and I. P.) were involved in various aspects of the conception and design of the study, acquisition of data and analysis and interpretation of data, and input into manuscript development. All authors had full access to all of the data in this study and take complete responsibility for the integrity of the data and accuracy of the data analysis. The sponsor did not place any restriction on authors about the statements made in the final article. The sponsor reviewed the publication to ensure medical and scientific accuracy and protection of intellectual property.

\section{Availability of data and materials}

Data underlying the findings described in this manuscript may be obtained in accordance with AstraZeneca's data sharing policy described at https:// astrazenecagrouptrials.pharmacm.com/ST/Submission/Disclosure.

\section{Ethics approval and consent to participate}

The study protocol was approved by an Independent Ethics Committee (NRES Committee - Cambridgeshire and Hertfordshire, Health Research Authority, Nottingham, UK; Reference No 15/EE/0329; see Additional file 1) and the UK Medicines and Healthcare Products Regulatory Agency. The informed consent form was also reviewed by the Independent Ethics Committee. The study was performed in accordance with the Declaration of Helsinki and the International Conference on Harmonization/Good Clinical Practice guidelines. All patients provided written, informed consent before enrolment in the study.

\section{Consent for publication}

Not applicable.

\section{Competing interests}

D. S. has received sponsorship to attend international meetings, honoraria for lecturing or attending advisory boards, and research grants from various pharmaceutical companies including Apellis, AstraZeneca, Boehringer Ingelheim, Chiesi, Cipla, Genentech, GlaxoSmithKline, Glenmark, Johnson and Johnson, Menarini, Mundipharma, Novartis, Peptinnovate, Pfizer, Pulmatrix, Skypharma, Teva, Therevance, and Verona. V. B., C. A., U. W. H., L. J., B. S., A. L., and I. P. are employees of AstraZeneca and may own stock or stock options. C. V. and A. A. were employees of AstraZeneca at the time the study was conducted. C. V. is a current employee of PAREXEL. A. A. is a current employee of Eloxx Pharmaceuticals. 


\section{Author details}

'The Medicines Evaluation Unit, Centre for Respiratory and Allergy Medicine, University of Manchester, University Hospital of South Manchester NHS Foundation Trust, M23 9QZ, Manchester, UK. ${ }^{2}$ Research and Early Development, Respiratory, Inflammation and Autoimmune, BioPharmaceuticals R\&D, AstraZeneca, Barcelona, Spain. ${ }^{3}$ Clinical Pharmacology and Quantitative Pharmacology, Clinical Pharmacology \& Safety Sciences, R\&D, AstraZeneca, Gothenburg, Sweden. ${ }^{4}$ Clinical Pharmacology and Quantitative Pharmacology, Clinical Pharmacology \& Safety Sciences, R\&D, AstraZeneca, Barcelona, Spain. ${ }^{5}$ Biometrics and Information Sciences, Late-Stage Development, BioPharmaceuticals R\&D, AstraZeneca, Barcelona, Spain. ${ }^{6}$ Late-Stage Development, BioPharmaceuticals R\&D; AstraZeneca, Barcelona, Spain. ${ }^{7}$ Patient Safety RIA, Chief Medical Office, R\&D, AstraZeneca, Barcelona, Spain. ${ }^{8}$ Research and Early Development, Respiratory, Inflammation and Autoimmune, BioPharmaceuticals R\&D, AstraZeneca, Boston, MA, USA. ${ }^{9}$ Research and Early Development, Respiratory, Inflammation and Autoimmune, BioPharmaceuticals R\&D, AstraZeneca, Gothenburg, Sweden.

Received: 23 March 2020 Accepted: 1 April 2020

Published: 9 September 2020

\section{References}

1. Global Initiative for Chronic Obstructive Lung Disease. Global Strategy for the Diagnosis, Management and Prevention of COPD, 2019.

2. Calzetta L, Rogliani P, Matera MG, et al. A systematic review with metaanalysis of dual bronchodilation with LAMA/LABA for the treatment of stable COPD. Chest. 2016;149:1181-96.

3. Calzetta L, Rogliani P, Ora J, et al. LABA/LAMA combination in COPD: a meta-analysis on the duration of treatment. Eur Respir Rev. 2017;26:160043.

4. Hughes $A D$, Jones LH. Dual-pharmacology muscarinic antagonist and $\beta 2$ agonist molecules for the treatment of chronic obstructive pulmonary disease. Future Med Chem. 2011;3:1585-605.

5. Cazzola M, Page CP, Calzetta L, et al. Pharmacology and therapeutics of bronchodilators. Pharmacol Rev. 2012;64:450-504.

6. Aparici M, Carcasona C, Ramos I, et al. Pharmacological profile of navafenterol (LAS191351), a novel inhaled dual M3 receptor antagonist/beta 2-Adrenoceptor agonist molecule with long-lasting effects and favorable safety profile. J Pharmacol Exp Ther. 2019;370:127-36.

7. Jimenez L, Astbury C, Seoane B, et al. A randomized placebo controlled trial of navafenterol a novel dual acting bronchodilator in asthmatics. Eur Respir J. 2017;50(Suppl. 61):PA1811.

8. Global Initiative for Chronic Obstructive Lung Disease. Global Strategy for the Diagnosis, Management and Prevention of COPD, 2015.

9. Donohue JF. Minimal clinically important differences in COPD lung function. COPD. 2005:2:111-24.

10. Bateman ED, Kornmann $\mathrm{O}$, Ambery $\mathrm{C}$, et al. Pharmacodynamics of GSK961081, a bi-functional molecule, in patients with COPD. Pulm Pharmacol Ther. 2013;26:581-7.

11. Bateman ED, Ferguson GT, Barnes N, et al. Dual bronchodilation with QVA149 versus single bronchodilator therapy: the SHINE study. Eur Respir J. 2013:42:1484-94.

12. Buhl R, Maltais F, Abrahams R, et al. Tiotropium and olodaterol fixed-dose combination versus mono-components in COPD (GOLD 2-4). Eur Respir J. 2015;45:969-79

13. Psallidas I, Singh D, Astbury C, et al. A phase 2a randomized, double-blind, placebo-controlled trial of navafenterol, a novel dual-acting bronchodilator in COPD patients. Am J Resp Crit Care Med. 2018;197:A7708.

14. Wielders PL, Ludwig-Sengpiel A, Locantore $\mathrm{N}$, et al. A new class of bronchodilator improves lung function in COPD: a trial with GSK961081. Eur Respir J. 2013:42:972-81.

15. Singh $D$, Fuhr $R$, Jimenez $L$, et al. A randomized trial of dual-acting bronchodilator navafenterol for chronic obstructive pulmonary disease. Am J Respir Crit Care Med. 2019;199:1282-4.

16. Battisti WP, Wager E, Baltzer L, et al. Good publication practice for communicating company-sponsored medical research: GPP3. Ann Intern Med. 2015;163:461-4.

\section{Publisher's Note}

Springer Nature remains neutral with regard to jurisdictional claims in published maps and institutional affiliations.

\section{Ready to submit your research? Choose BMC and benefit from}

- fast, convenient online submission

- thorough peer review by experienced researchers in your field

- rapid publication on acceptance

- support for research data, including large and complex data types

- gold Open Access which fosters wider collaboration and increased citations

- maximum visibility for your research: over $100 \mathrm{M}$ website views per year

At $\mathrm{BMC}$, research is always in progress.

Learn more biomedcentral.com/submissions 